\title{
Credit Rating Model of Small Enterprises Based on Optimal Discriminant Ability and Its Empirical Study
}

\author{
Zhanjiang Li $(i)$ and Lin Guo \\ College of Economics and Management, Inner Mongolia Agricultural University, Hohhot, China \\ Correspondence should be addressed to Zhanjiang Li; lizhanjiang582@163.com
}

Received 25 September 2021; Accepted 23 October 2021; Published 5 November 2021

Academic Editor: Sameh S. Askar

Copyright $\odot 2021$ Zhanjiang Li and Lin Guo. This is an open access article distributed under the Creative Commons Attribution License, which permits unrestricted use, distribution, and reproduction in any medium, provided the original work is properly cited.

\begin{abstract}
As an important part of the national economy, small enterprises are now facing the problem of financing difficulties, so a scientific and reasonable credit rating method for small enterprises is very important. This paper proposes a credit rating model of small enterprises based on optimal discriminant ability; the credit score gap of small enterprises within the same credit rating is the smallest, and the credit score gap of small enterprises between different credit ratings is the largest, which is the dividing principle of credit rating of small enterprises based on the optimal discriminant ability. Based on this principle, a nonlinear optimization model for credit rating division of small enterprises is built, and the approximate solution of the model is solved by a recursive algorithm with strong reproducibility and clear structure. The small enterprise credit rating division not only satisfies the principle that the higher the credit grade, the lower the default loss rate, but also satisfies the principle that the credit group of small enterprises matches the credit grade, with credit data of 3111 small enterprises from a commercial bank for empirical analysis. The innovation of this study is the maximum ratio of the sum of the dispersions of credit scores between different credit ratings and the sum of the dispersions of credit scores within the same credit rating as the objective function, as well as the default loss rate of the next credit grade strictly larger than the default loss rate of the previous credit grade as the inequality constraint; a nonlinear credit rating optimal partition model is constructed. It ensures that the small enterprises with small credit score gap are of the same credit grade, while the small enterprises with large credit score gap are of different credit grades, overcoming the disadvantages of the existing research that only considers the small enterprises with large credit score gap and ignores the small enterprises with small credit score gap. The empirical results show that the credit rating of small enterprises in this study not only matches the reasonable default loss rate but also matches the credit status of small enterprises. The test and comparative analysis with the existing research based on customer number distribution, K-means clustering, and default pyramid division show that the credit rating model in this study is reasonable and the distribution of credit score interval is more stable.
\end{abstract}

\section{Introduction}

Credit rating plays an extremely important role in the global economy. The unreasonable classification of credit rating may lead to the bankruptcy of enterprises, banks, and other institutions at the least or to financial crisis at the worst. For example, in 2011, Standard \& Poor's downgraded the sovereign credit rating of the United States from AAA to AA, causing shocks in the global financial market [1]. With the increasing social development and people's demand, small enterprises are playing an increasingly important role and making great contributions to the development of national economy. However, due to the characteristics of small enterprises, such as imperfect financial information and nonstandard management, their credit rating is difficult; and, in order to reduce the credit risk, banks and other financial institutions adopt the strategy of reluctance or even not lending to small enterprises, which leads to the difficulty of small enterprises in loan and financing and restricts their development. Therefore, reasonable and scientific credit rating method can enable enterprises to effectively predict their own risk status and timely adjustment of capital structure and reduce the credit risk, and it can provide a basis for banks to make loan pricing and loan decisions, 
reduce the potential loss of banks, improve the profitability and core competitiveness of banks, and contribute to the stability of the financial market. This paper proposes a credit rating model of small enterprises based on optimal discriminant ability, which not only matches the reasonable default loss rate but also matches the credit status of small enterprises. This plays a very important role in alleviating the financing difficulties of small enterprises and strengthening the risk control of banks and other financial institutions.

At present, the research on enterprise credit rating is mainly divided into four aspects. The first is a credit rating based on a customer's score. According to the customer's credit score, Bank of China classified the enterprise into ten credit grades, such as AAA, AA, A, BBB, BB, B, and CCC; customers with credit scores of $[90,100]$ were classified as AAA and $[80,90)$ as AA, with each credit rating decreased by 10 points [2]. Agricultural Bank of China divided customers into eight credit grades, namely, AAA+, AAA, AA+, AA, A+, $A, B$ and C; customers with credit scores of $[95,100]$ were classified as AAA+, $[90,95)$ as AAA, and so forth. For every five points that a customer's credit score dropped, it dropped one credit grade [3]. Moon et al. proposed a technology credit rating system based on empirical data of the technology scoring model, called the crossover matrix, which divided customers into ten credit grades according to their credit scores. Customers with credit scores greater than 90 were classified as AAA, those with credit scores between 85 and 89 were classified as AAA, and so forth [4]. The second is the credit ratings based on the probability of default. Gupton, based on the credit measurement model of Credit Metrics, divided the loan customers into eight credit grades of AAA, AA, A, BBB, BB, B, CCC, and D according to their different default probabilities [5]. Lyra et al. divided default probability through threshold acceptance method and proposed a new method to calculate the number of defaults of each credit grade to verify the accuracy of the rating system [6]. Zhang used the characteristic function to describe the characteristics of the number of loans during the investigation period and proposed a default probability measurement method based on default intensity, which provided a new idea for banks and other financial institutions to conduct credit rating [7]. Zhu et al. divided enterprises into five credit grades, A, B, C, D, and E, through Lasso logistic regression. Enterprises with default probability less than 0.2 were classified as A, $0.2-0.3$ as B, $0.3-0.4$ as C, and $0.4-0.5$ as $\mathrm{D}$. Enterprises with default probability greater than 0.5 were classified as grade E [8]. The third is the credit rating based on the distribution of the number of customers. Duan and $\mathrm{Li}$ improved the $\mathrm{PD}$-implied rating (PDiR) methodology by targeting the historical credit migration matrix rather than simply default rates to classify credit grades [9]. Chi et al. expanded the small sample according to the logarithmic distribution law and finally divided customers into 9 credit grades based on the bell-shaped distribution. The results showed that the rating results of this model are consistent with those of authoritative institutions [10]. According to the bell-shaped distribution of the number of customers, Chi et al. divided peasant households' credit scores into 9 credit grades, such as AAA, AA, and A, so as to avoid the unreasonable phenomenon of excessive concentration of samples in AAA or C levels and ensure that most samples are concentrated in A and BBB levels [11]. Zhang and Chi established a multiobjective programming model with the minimum absolute value of the difference between the actual customer ratio and the ideal customer ratio based on normal distribution as the first objective function and the minimum difference between the loss rates of adjacent credit grades as the second objective function. The results showed that this method not only ensured the balance between the two criteria but also avoided the phenomenon of excessive concentration of customers on specific credit ratings [12]. The last is a credit rating based on default loss rates. On the basis of considering the default loss rate, Zhao et al. maximized the sum of the difference between the credit score of the last sample of the previous credit grade and the first sample of the next credit grade as the objective function and established the credit rating model with the strict increase of the default loss rate of each grade as the constraint condition, so as to ensure that customers with large credit differences are divided into different credit grades [13]. Shi et al. took the maximum number of loan merchants above the critical point of the bank's target profit and the smallest gap in the default loss rate of adjacent merchants as the objective function and the increasing default loss rate and the realization of the bank's target profit as the constraint conditions. A multiobjective programming model is constructed to classify credit ratings, which can ensure that banks can achieve the target profit [14]. Chi and Yu took the maximum algebraic sum of the maximum absolute values of the difference between the cumulative frequency of nondefaulting customers and the cumulative frequency of defaulting customers as the objective function, with the loss rate of each credit grade strictly increasing as the main constraint condition; a credit rating model was built to ensure that credit grades could significantly distinguish customers with large differences in default possibilities [15]. Shi et al. proposed a credit rating model based on the influence of key macroeconomic variables on credit decisions of commercial banks and loss given default (LGD) and conducted an empirical analysis based on the bank data of 2,044 farmers in China. The results showed that, in some cases, a higher credit rating may lead to a higher LGD [16]. Later, in order to solve the mismatch between credit ratings and default loss rate, Shi et al. proposed a risk rating matching standard to minimize the default loss rate of high credit rating loans and tested the method using three credit datasets from China [17]. Zhou (2021) sorted loan enterprises according to their credit scores from high to low and then found the credit rating results that meet the higher credit rating and lower default loss rate by adjusting the upper and lower limits of credit scores of each grade [18].

Existing credit rating research is divided from the perspectives of customer credit score [2-4], default probability [5-8], and customer number distribution [9-12]; the actual default loss rate of customers is not taken into account, so it may occur that the customer has not only a higher credit grade but also a higher default loss rate. In addition, although there is some research on credit rating from the perspective of default 
loss rate [13-18], it is not strictly guaranteed that customers with small credit score gap can be divided into the same credit grade, while customers with large credit score gap can be divided into different credit grades. In view of the above situation, this paper constructs a nonlinear optimal credit rating model, which not only ensures that the credit rating matches the default loss rate but also ensures that the credit rating matches the credit status of small enterprises.

The contribution of this paper is mainly divided into two aspects. First, we propose a credit rating model of small enterprises based on optimal discriminant ability, the maximum ratio of the sum of the dispersions of credit scores between different credit ratings and the sum of the dispersions of credit scores within the same credit rating as the objective function, and the default loss rate of the next credit grade strictly larger than the default loss rate of the previous credit grade as the inequality constraint, as well as through recursive algorithm to solve the model. It ensures that the small enterprises with small credit score gap are of the same credit grade, while the small enterprises with large credit score gap are of different credit grades, which overcomes the disadvantages of the existing research that only considers the small enterprises with large credit score gap and ignores the small enterprises with small credit score gap.

Second, we make empirical analysis of the credit data of 3111 small enterprises from a commercial bank and make comparative analysis with the small business credit rating model based on the distribution of the number of customers, the K-means clustering, and the default pyramid. The results show that the credit rating model constructed in this paper based on the optimal discriminant ability is reasonable and the interval distribution of credit score is more stable.

The article is organized as follows. Section 2 discusses the principle of credit rating model construction; Section 3 describes the methodology of credit rating model construction; Section 4 explains the specific process of credit rating model construction, tests the model, and compares the model to the traditional models; and Section 5 draws conclusions and summarizes the innovative points of the research.

\section{Principle of Credit Rating Model Based on Optimal Discriminant Ability}

2.1. Principle of Credit Rating Model. The first principle is that the credit rating matches the default loss rate. A higher credit grade should correspond to a lower default loss rate, and a lower credit grade should correspond to a higher default loss rate. If the credit rating of a small enterprise does not meet this principle, when the credit grade of small enterprise is high, banks and other financial institutions will give the enterprise a lower loan interest rate, but the high default loss rate of the enterprise indicates that the default risk of the enterprise is high, and the banks and other financial institutions may face the risk of not receiving the principal and interest back. When the credit rating of small enterprises is low and the default loss rate is low, the bank and other financial institutions will refuse the loan or loan at a higher interest rate, and the bank will also face the risk of customer loss.
The second principle is that the credit rating matches the credit status of small enterprises. Credit rating should ensure that small enterprises with small credit score gaps are divided into the same credit grade and small enterprise with large credit score gaps are divided into different credit grades. If the credit rating cannot identify the default risk of small enterprises to the maximum extent, it is unreasonable that small enterprises with high default risk and small enterprises with low default risk are in the same credit grade. As a result, the credit rating of small enterprises is chaotic, which is not conducive to the loan pricing and decisionmaking of banks and other financial institutions.

\subsection{The Difficulty of the Problem}

Difficulty 1 . The first difficulty of this study is how to avoid ineffective and multiple random classification of credit grade in the case of large sample size.

Difficulty 2. The second difficulty of this study is how to ensure that the credit rating can identify the default risk of small enterprises to the greatest extent, so that small enterprises with small credit score gap are in the same credit grade, and small enterprises with large credit score gap are in different credit grades.

\subsection{The Method to Solve the Difficulty}

The Method to Solve Difficulty 1. The credit rating should meet the principle of matching the credit rating with the default loss rate. The constraint condition is that the default loss rate of the following credit grade is strictly higher than the default loss rate of the previous credit grade. A nonlinear optimization model is constructed to divide the credit grade and ensure that the divided credit grade matches the default loss rate.

The Method to Solve Difficulty 2. The maximum sum of credit score deviations between different credit grades indicates that the credit score gap of small enterprises with different credit grades is large, while the minimum sum of credit score deviations within the same credit grade indicates that the credit score gap of small enterprises with same credit grade is small. Therefore, the maximum ratio of the sum of the deviations of credit scores between different credit grades and the sum of the deviations within the same grade is taken as the objective function, and a nonlinear optimization model is built to divide credit grades to ensure that the divided credit grades match the credit status of small enterprises.

The principle of credit rating model for small enterprises based on optimal discriminant ability is shown in Figure 1.

\section{Construction of Credit Rating Model Based on Optimal Discriminant Ability}

3.1. Establishment of the Objective Function. Assume that $K$ is the number of credit ratings; $N$ is the total number of small enterprises; $n_{k}$ is the number of small enterprises with credit rating $k ; \bar{S}^{k}$ is the average credit score for small enterprises 


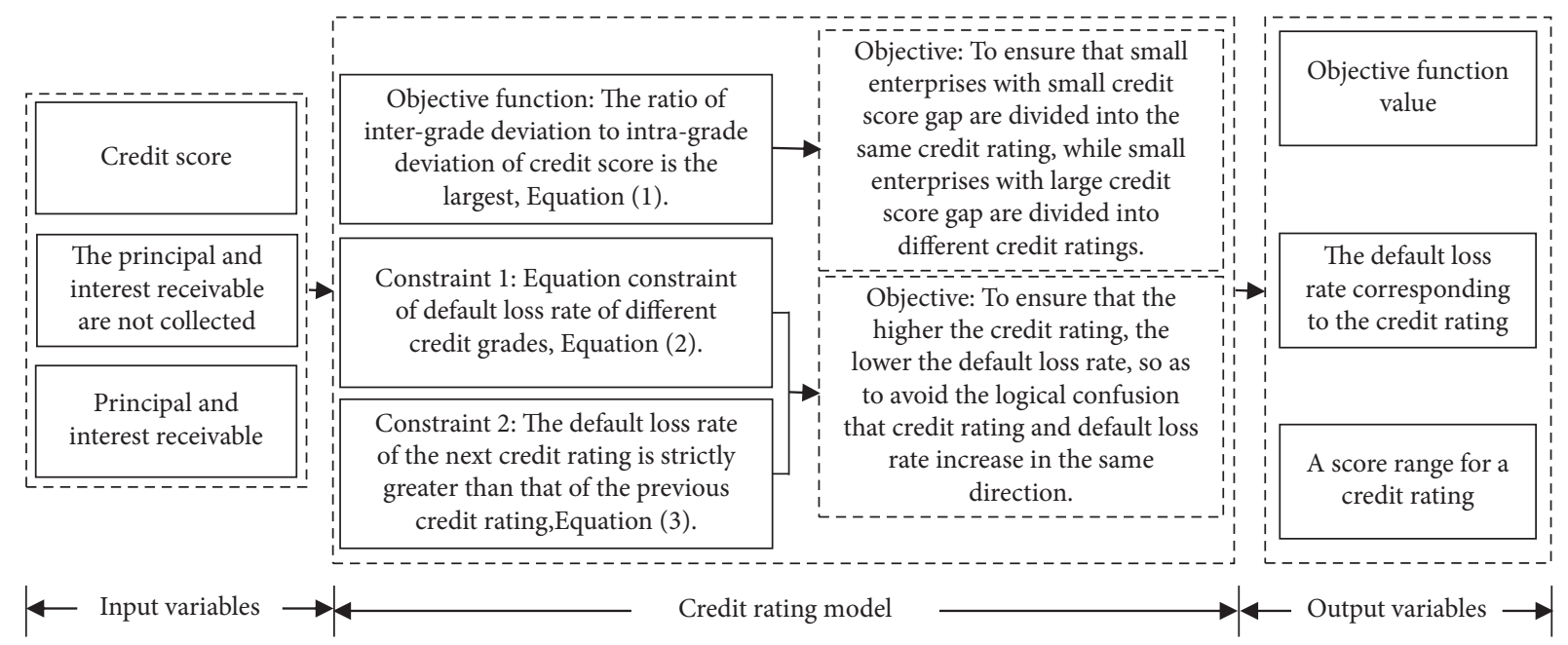

Figure 1: The principle of credit rating model for small enterprises based on optimal discriminant ability.

with credit rating $k ; \bar{S}$ is the average of all small enterprise credit scores; $q_{k}$ is an artificial positive weighting factor; $q_{k}$ here takes the prior probability $n_{k} / N ; \sigma_{k}^{2}$ is the variance of the credit score of small enterprises with credit rating $k$. The objective function is as follows [19]:

$$
\text { Obj: } \max f=\frac{\sum_{k=1}^{K} n_{k}\left(\bar{s}^{k}-\bar{s}\right)^{2}}{\sum_{k=1}^{K} q_{k} \sigma_{k}^{2}} .
$$

Regarding the economic meaning of equation (1), the molecule of the objective function is the difference between the mean value of the credit scores of small enterprises of each credit grade and the mean value of the credit scores of all small enterprises; the larger the value is, the larger the credit score gap of small enterprises with different credit grades is. The denominator is the credit score deviation of small enterprises within each credit grade; the smaller this value is, the smaller the credit score gap of small enterprises with the same credit grade is. The objective function reflects the principle that credit rating should match the credit status of small enterprises.

For the difference between equation (1) and existing research [13], existing research only considers small enterprises with large credit score gaps and ignores small enterprises with small credit score gaps. This study also considered small enterprise groups with large and small credit score gaps; it avoids the logical confusion that small enterprises with large credit score gaps are divided into the same credit grade, while small enterprises with small credit score gaps are divided into different credit grades.

As regards innovation of equation (1), taking the maximized ratio of the sum of the dispersion of credit scores between different credit grades and the sum of the dispersion of credit scores within the same credit grade as the objective function, a nonlinear optimal division model of credit ratings is established. It ensures that groups of small enterprises with small credit score gaps are divided into the same credit grade and groups of small enterprises with large credit score gaps are divided into different credit grades, and it overcomes the disadvantage that the existing research only considers the small enterprises with large credit score gap and ignores the small enterprises with small credit score gap.

\subsection{Establishment of Constraints}

3.2.1. Establishment of the Equation Constraint of Default Loss Rate. Assume that $L G D_{k}$ is the default loss rate of the $k$ th credit rating; $L_{k i}$ is the annual receivable and uncollected principal and interest of the $i$ th small enterprise with the $k$ th credit rating; $G_{k i}$ is the annual receivable principal and interest of the $i$ th small enterprise with the $k$ th credit rating. The default loss rate of the $k$ th credit rating is as follows [13]:

$$
L G D_{k}=\frac{\sum_{i=1}^{n_{k}} L_{k i}}{\sum_{i=1}^{n_{k}} G_{k i}} .
$$

Regarding the economic meaning of equation (2), the default loss rate of each credit grade is the ratio of the sum of the receivable and uncollected principal and interest of all the small enterprises in the grade to the sum of the receivable principal and interest of all the small enterprises in the grade.

For the function of equation (2), the calculation of the default loss rate based on the annual receivable and uncollected principal and interest and annual receivable principal and interest of small enterprises can truly reflect the losses of banks and other financial institutions, avoiding the disadvantages of dividing credit grade only based on default probability and customer number distribution that cannot reflect the real losses of banks.

\subsubsection{Establishment of Inequality Constraint of Default Loss} Rate. In the division of credit grade, the default loss rate of the next credit grade is strictly higher than the default loss rate of the previous credit grade. The inequality constraint of the default loss rate is as follows [13]:

$$
\text { s.t.: } 0<L G D_{1}<L G D_{2}<\ldots<L G D_{k-1}<L G D_{k} \leq 1 \text {. }
$$

Regarding the economic meaning of equation (3), in practice, only national debt is risk-free; that is, the default 
loss rate is 0 , so the default loss rate corresponding to the highest credit rating should be greater than 0 . When the default loss rate is 1 , it means that all the small enterprises corresponding to this grade are in default, which is possible in practice, so the default loss rate corresponding to the lowest credit grade should be less than or equal to 1 .

For the function of equation (3), the default loss rate of the next credit grade is strictly higher than the default loss rate of the previous credit grade as the constraint condition for constructing the credit rating model. It ensures that, with the decrease of credit ratings, the corresponding default loss rate rises, which meets the principle that the credit rating should match the default loss rate, and it avoids the unreasonable phenomenon that the credit grade is high but the corresponding default loss rate is also high.

3.3. Solution of Credit Rating Model. This research mainly adopts the recursive idea to solve the credit rating model. Here, it directly uses the 9 divided credit grades to illustrate. The specific steps of solving are as follows:

Step 1: Rank small enterprises by credit score from largest to smallest, as shown in columns (2)-(4) of Table 1.

Step 2: Set the credit grade number $K$ and the threshold value of the objective function.

Step 3: We randomly select a AAA credit grade and then a AA credit grade and calculate the default loss rate for each grade. If the default rate of $\mathrm{AA}$ is lower than the default rate of AAA, the AAA grade is reselected at random; if the constraint conditions are satisfied, then we continue to randomly select the credit grade of A and so on, so as to obtain multiple groups of credit rating results satisfying the constraint conditions.

Step 4: We put the credit scores of several groups of small enterprises satisfying the constraint conditions into the objective function and select the credit rating results whose objective function value is greater than the threshold value. At this time, the credit rating results obtained are a set of solutions under the threshold value of the objective function.

Step 5: Select the critical value of the threshold according to the operating efficiency, increase the threshold of the objective function continuously, and continue to repeat Steps 3 and 4 . When the objective function value is close to the critical value of the threshold, the dichotomy is used to continuously approach the threshold value to determine the global optimal solution, and the final result of credit rating is obtained. The detailed flowchart is shown in Figure 2.

\subsection{Test of Credit Rating Model}

3.4.1. Purpose of the Test. Through the test, it is proved that the nonlinear optimization model of credit rating constructed in this study is reasonable and stable.
3.4.2. Test Formula. Use STDEV index value to test the stability of the credit score interval distribution. Assume that $I_{k}$ is the length of the credit score interval of the $k$ th credit grade; $\bar{I}$ is the mean length of credit score interval of all $K$ credit grades. The STDEV index value is as follows [20]:

$$
\mathrm{STDEV}=\sqrt{\frac{\sum_{i=1}^{K}\left(I_{k}-\bar{I}\right)^{2}}{K-1}} .
$$

Regarding the economic meaning of equation (4), the smaller the STDEV index value is, the more stable the distribution of credit score interval is.

\subsubsection{Test Standards}

(1) Reasonableness Standard. If the final credit rating results meet the standard that the default loss rate increases with the decline of credit rating, it indicates that the credit rating model constructed in this study is reasonable.

(2) Stability Standard. By comparison with other models, the smaller the STDEV index value of the credit rating model constructed in this study is, the more stable the distribution of credit score interval in this study is.

\section{Empirical Study}

4.1. Sample Source. This study selects the loan data of 3111 small enterprises from a Chinese commercial bank as the empirical sample, including 3040 nondefaulting small enterprises and 71 defaulting small enterprises. The construction process of credit evaluation index system of small enterprises is derived from literature [21], and the results are listed in column 3 of Table 2. The index weights are obtained through logistic regression, and the results are listed in column 4 of Table 2 . The standard credit score can be obtained based on the weight of the indicators and standardized data for small enterprises and are listed in column 2 of Table 1 in a descending order. It should be pointed out that the construction of the indicator system of small enterprises, the determination of the weight of the indicator, and the measurement of the credit score are not part of the content of this study, so they will not be repeated here. The specific results are shown in Tables 1 and 2.

4.2. Determination of Credit Rating Results. Based on the credit ratings of the international rating agencies Standard \& Poor's and Moody's, this study divides small enterprises into 9 credit grades, namely, AAA, AA, A, BBB, BB, B, CCC, CC, and $\mathrm{C}$; that is, $\mathrm{K}$ is 9 .

4.2.1. Credit Rating Satisfying Constraint Conditions and Threshold of Objective Function. The threshold value of the objective function 35000 and a randomly selected credit rating that meets the constraint conditions are taken as an example to illustrate. 
TABLE 1: Small enterprise credit rating data.

\begin{tabular}{lcccc}
\hline (1) No. & $\begin{array}{c}\text { (2) Standard credit } \\
\text { score }\end{array}$ & $\begin{array}{c}\text { (3) Receivable principal and } \\
\text { interest }\end{array}$ & $\begin{array}{c}\text { (4) Receivable and uncollected principal and } \\
\text { interest }\end{array}$ & $\begin{array}{c}\text { (5) Default } \\
\text { status }\end{array}$ \\
\hline 1 & 100.0000 & 2160388.94 & 0.00 & 0 \\
$\ldots$ & $\ldots$ & $\ldots$ & $\ldots$ & $\ldots$ \\
1408 & 81.2203 & 32340576.16 & 29855947.12 & 1 \\
1409 & 81.1925 & 8443839.30 & 0.00 & $\ldots$ \\
$\ldots$ & $\ldots$ & $\ldots$ & 78904.72 & $\ldots$ \\
3111 & 0.0000 & 78904.72 & $\ldots$ & 1 \\
\hline
\end{tabular}

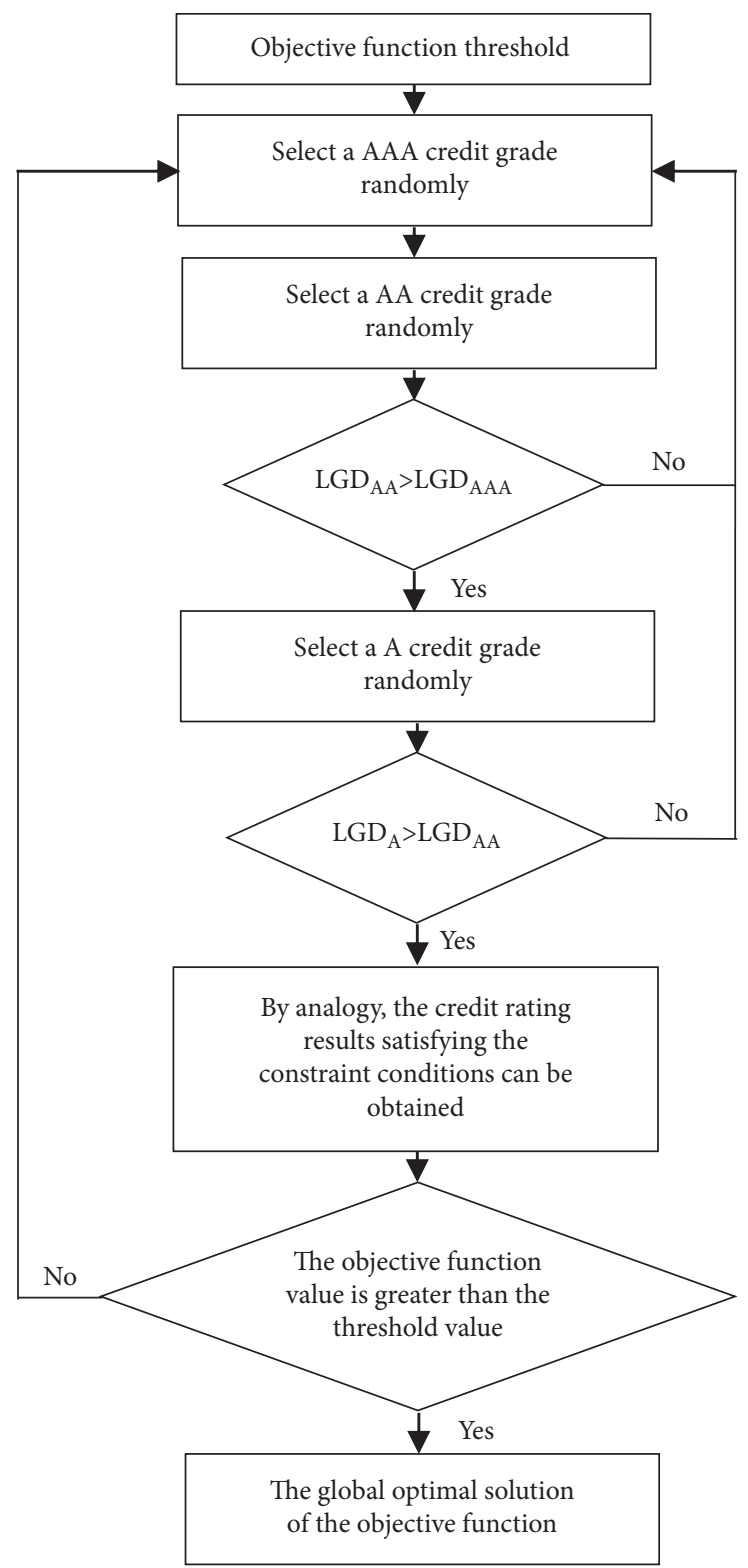

FIGURE 2: Flowchart of solving credit rating model.

(1) Credit Rating Satisfying Constraint Conditions. The standard credit score $S_{i}$, receivable principal and interest $G_{i}$, receivable and uncollected principal and interest $L_{i}$, and the default status of small enterprises are listed in the relevant columns in Table 1 according to the credit score from large to small.
Select a AAA credit grade and a AA credit grade at random. Assume that the number of small enterprises with AAA credit grade is 1502 and the number of small enterprises with AA credit grade is 288; that is, the starting and ending numbers of small enterprises with AAA credit grade and AA credit grade are [1-1502] and [1503-1790], 
TABLE 2: Small enterprise credit index system and weight.

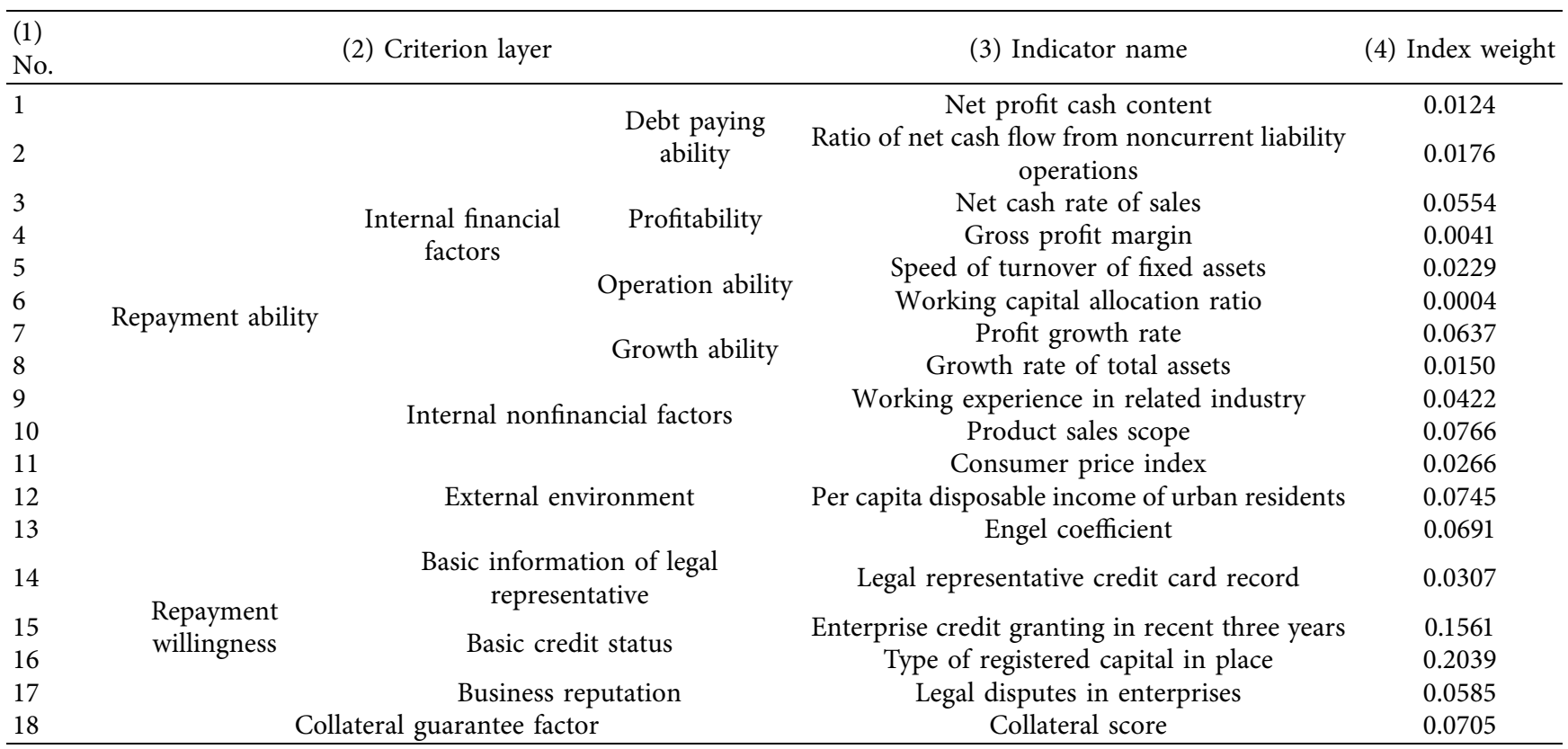

respectively. Substitute the sum value of the receivable and uncollected principal and interest and the sum value of the receivable principal and interest of the small enterprises in these two grades into equation (2), respectively:

$$
\begin{aligned}
\mathrm{LGD}_{\text {AAA }} & =\frac{34465964}{5927398089.27}=0.0058, \\
\mathrm{LGD}_{\mathrm{AA}} & =\frac{3784389.75}{1412429040.39}=0.0027 .
\end{aligned}
$$

The default loss rate of AAA credit grade is higher than that of AA credit grade, indicating that AAA and AA credit grades do not meet the constraint conditions. Therefore, the numbers of small enterprises with AAA and AA credit grade are randomly selected again.

Assume that the numbers of small enterprises with AAA credit grade and AA credit grade reselected at random are 1783 and 127, respectively; that is, the starting and ending numbers of small enterprises with AAA and AA credit grades are [1-1783] and [1784-1909], respectively. Continue to substitute their sum values of receivable and uncollected principal and interest and their sum values of receivable principal and interest into equation (2), respectively:

$$
\begin{gathered}
\operatorname{LGD}_{\text {AAA }}=\frac{38250353.46}{7300129899.68}=0.0052, \\
\operatorname{LGD}_{\text {AA }}=\frac{9255986.32}{998518502.37}=0.0093 .
\end{gathered}
$$

At this point, the default loss rate of AAA credit grade is less than that of AA, indicating that AAA credit grade and
AA credit grade meet the constraint conditions, so A credit grade is selected at random.

Assume that the number of randomly selected small enterprises with A credit grade is 619; that is, the starting and ending number of small enterprises with A credit grade is [1910-2527]. Substitute the sum value of the receivable and uncollected principal and interest and the sum value of the receivable principal and interest of the small enterprise with this credit rating into equation (2):

$$
\operatorname{LGD}_{A}=\frac{485412345.04}{6363741983.55}=0.0763 \text {. }
$$

At this point, the default loss rate of AA credit grade is less than that of $\mathrm{A}$, indicating that $\mathrm{AA}$ credit grade and $\mathrm{A}$ credit grade meet the constraint conditions. Therefore, $\mathrm{BBB}$ grade is selected at random. If the default loss rate of $\mathrm{AA}$ credit grade is greater than that of $\mathrm{A}$, it means that $\mathrm{AA}$ and $\mathrm{A}$ credit grades do not meet the constraint conditions, and then AAA credit grade shall be reselected.

Assume that the number of small enterprises with BBB credit grade randomly selected is 176 ; that is, the starting and ending number of small enterprises with $\mathrm{BBB}$ credit grade is [2528-2702]. Substitute the sum value of the receivable and uncollected principal and interest and the sum value of the receivable principal and interest of the $\mathrm{BBB}$ credit rating small enterprise into equation (2):

$$
\operatorname{LGD}_{\text {Bвв }}=\frac{197741326.45}{2540497356.76}=0.0778 \text {. }
$$

At this point, the default loss rate of A credit grade is less than that of $\mathrm{BBB}$, indicating that $\mathrm{A}$ and $\mathrm{BBB}$ credit grades 
meet the constraint conditions, so BB credit grade is selected at random. If the default loss rate of $A$ credit grade is greater than that of $\mathrm{BBB}$ at this time, it means that $\mathrm{A}$ and $\mathrm{BBB}$ credit grades do not meet the constraint conditions, and then the AAA credit grade shall be reselected.

By analogy, a set of credit rating results satisfying the constraint conditions can be obtained. The default loss rates of the nine credit grades are 0.0052, 0.0093, 0.0763, 0.0778, $0.1429,0.1770,0.2801,0.4863$, and 0.5000 , respectively. The starting and ending numbers of small enterprises with nine credit grades are [1-1783], [1784-1909], [1910-2527], [2528-2702], [2703-3035], [3036-3104], [3105-3107], [3107-3109], and [3110-3111].

Since the number of small enterprises in each credit grade is randomly selected and there is no constraint of objective function threshold, multiple groups of credit rating results satisfying the constraint conditions can be obtained.

(2) Credit Rating Satisfying the Threshold of Objective Function. Since the maximum value of the objective function is required to be solved in this study, the threshold value of the objective function needs to be continuously increased to obtain the optimal solution, so the critical value of the threshold value of the objective function is extremely critical.

The threshold value of the objective function in this study is selected according to the actual running efficiency of the program. We first select 5000 and then continue to increase the threshold at intervals of 5000, such as 10000 , 15000 , and 20000, until the threshold increases to 45000 , and the program will run less efficiently. Therefore, 45000 is taken as the threshold critical value of the objective function in this study. Due to the limitation of conditions, the threshold value of the objective function selected in this study is 45000 , and the threshold value can be further increased to further increase the objective function value, so as to obtain more superior results of credit rating division.

When the threshold value of the objective function is 35000 , according to (1), a set of credit ratings satisfying the constraint conditions will be obtained first, as shown in row 1 of Table 3. Substitute the credit scores of small enterprises corresponding to each credit grade into equation (1):

$$
f_{1}=\frac{425565.14}{18.18}=23410.04 \text {. }
$$

Since the objective function value of the first group of credit rating results is less than the threshold value of 35000 , AAA and AA credit grades should be randomly selected again until the second group of credit rating results meeting the constraint conditions is obtained, as shown in row 2 of Table 3. Continue to substitute its corresponding credit score into equation (1):

$$
f_{2}=\frac{403417.05}{25.30}=15946.58 .
$$

Since the objective function value of the second group of credit rating results is still less than the threshold value of 35000 , it is necessary to continue to randomly select AAA and AA credit grades to obtain the credit rating results of the third group, the fourth group, and the fifth group that meet the constraint conditions, until the objective function value is greater than the threshold value of 35000 .

The credit rating results satisfying the constraint conditions are shown in row 9 of Table 3; that is, the results are listed in process (1) above. Substitute the credit score of the corresponding small enterprise into equation (1):

$$
f_{9}=\frac{444819.33}{11.99}=37100.18
$$

At this time, the objective function value corresponding to the credit rating result is greater than the threshold value of 35000 , so the credit rating result of this group is a solution of the threshold value of 35000 .

What needs to be noted here is that the operation will stop immediately when the credit rating division meeting the constraint conditions appears and the objective function value is greater than 35000 . Therefore, the nine groups of division results obtained here are not the results that all meet the constraint conditions when the objective function value is greater than 35000; and, with the number of runs, the results are not exactly the same. The specific results are shown in Table 3.

4.2.2. Determination of the Global Optimal Solution. Taking the threshold of objective function 45000 as the boundary, the global optimal solution is approximated by dichotomy. When the threshold value of the objective function is 40000 , the credit rating result can still be obtained, and it is close to the critical value. Therefore, 40000 is taken as the starting point here to illustrate the specific process of the dichotomy approach to the global optimal solution.

(1) The First Approximation to the Global Optimal Solution. Firstly, the threshold value of the objective function is set as 40000. According to the above process, we can first obtain a solution that satisfies the constraint conditions and the objective function is greater than the threshold value of 40000 , that is, a group of credit rating results with the objective function value of 41742 .

Continuing on the basis of the above process, we can get another solution that satisfies the constraint conditions and the objective function is greater than the threshold value of 40000 , that is, another set of credit rating results with the objective function value of 42650 .

Based on the dichotomy, we can calculate and obtain the threshold of the next objective function that approximates the global optimal solution; that is,

$$
41742+\frac{(42650-41742)}{2}=42196
$$

(2) The Second Approximation to the Global Optimal Solution. When the objective function threshold is 42196 , we can get one solution with the objective function value of 42643 and another solution with the objective function value of 
TABLE 3: Credit rating division of 9 groups satisfying constraint conditions.

\begin{tabular}{lccccccccc}
\hline No. & $(1)$ AAA & $(2)$ AA & $(3)$ A & $(4)$ BBB & (5) BB & (6) B & (7) CCC & (8) CC & $(9)$ C \\
\hline 1 & 2215 & 2682 & 2765 & 2771 & 3033 & 3105 & 3107 & 3109 \\
2 & 2517 & 2680 & 2728 & 2777 & 3024 & 3100 & 3107 & 3110 \\
3 & 2366 & 2688 & 2735 & 2754 & 3028 & 3106 & 3107 & 3111 \\
4 & 2447 & 2689 & 2765 & 2770 & 3034 & 3105 & 3107 & 3108 \\
5 & 1744 & 2129 & 2693 & 2764 & 3031 & 3100 & 3107 & 3109 \\
6 & 2657 & 2688 & 2738 & 2753 & 3026 & 3105 & 3107 & 311 \\
7 & 2493 & 2690 & 2766 & 2770 & 3030 & 3099 & 3107 & 3110 \\
8 & 1654 & 1806 & 2763 & 2771 & 3032 & 3104 & 3107 & 311 \\
9 & 1783 & 1909 & 2527 & 2702 & 3035 & 3104 & 3107 & 3111 \\
\hline
\end{tabular}

42657. Therefore, the objective function threshold of the third approximation to the global optimal solution is

$$
42643+\frac{(42657-42643)}{2}=42650
$$

(3) Obtaining the Global Optimal Solution. When the objective function threshold is 42650 , we can obtain the credit rating result with the objective function value of 44951 . At this time, the default loss rate of each credit grade obtained is less different from that obtained in the process of approaching the global optimal solution for several times. Moreover, the objective function value is the maximum value when the threshold critical value is 45000 . Therefore, the credit rating result obtained when the objective function value is 44951 is taken as the global optimal solution. The above process is solved by MATLAB programming. The specific results are shown in Table 4. The following LGD is the default loss rate, which is listed in the form of percentages.

4.2.3. Credit Rating Results Analysis. When the objective function value is 44951, the sample number and default loss rate corresponding to each credit grade are listed in column 2 and column 6 of Table 5 respectively. The credit score interval is determined by the credit score of the last small enterprise in each credit grade and is listed in column 4 of Table 5. The interval length is the value of the right endpoint of the credit score interval minus the left endpoint. The maximum value of the interval length is 31.3853 , and the minimum value of the interval length is 1.6911 , which has obvious differentiation and is listed in column 5 of Table 5 . The specific results are shown in Table 5 .

As can be seen from column 6 of Table 5, the default loss rate of the nine credit grades, such as AAA credit grade and AA credit grade, is strictly increasing, that is, $0<0.52 \%<5.49 \%$ $<7.65 \%<15.42 \%<17.88 \%<20.84 \%<23.01 \%<94.82 \%$ $<100.00 \%<1$, indicating that the final credit rating result obtained in this study meets the principle that the default loss rate increases with the continuous reduction of credit grade.

The objective function value corresponding to the credit rating result shown in Table 5 is the maximum value that can be obtained when the threshold critical value is 45000 , indicating that the credit rating result can ensure that the sum of the dispersions of credit scores between small enterprises with different credit grades is the largest, and the sum of the dispersions of credit scores for small enterprises within the same credit grade is the smallest. That is, small enterprises with large credit score gap can be divided into different credit grades, while small enterprises with small credit score gap can be divided into the same credit grade, indicating that the credit rating model constructed in this study meets the principle of matching credit rating with the credit status of small enterprises.

By plotting the credit grade in column 3 of Table 5 and the default loss rate in column 6 , the relationship between credit grade and default loss rate can be shown more intuitively. The horizontal axis is the length of the default loss rate, and the vertical axis is the corresponding credit grade, as shown in Figure 3. It is important to note that as the number of empirical samples increases, the credit score interval becomes more uniform and Figure 3 becomes smoother.

\subsection{Test and Comparative Analysis of Credit Rating Model}

\subsubsection{Credit Rating Results of Comparative Model}

(1) Credit Rating Based on the Distribution of the Number of Customers. The sample proportion of each credit grade is determined according to the existing literature [11] on credit rating based on the normal distribution of the number of customers, which is listed in column 2 of Table 6 . Then the sample number of small enterprises of each credit grade is calculated to get the starting and ending number of small enterprises of each credit grade, which is listed in column 1 of Table 6. The calculations of credit score interval, interval length, and default loss rate are the same as above, which are, respectively, listed in columns $4-6$ of Table 6 . The specific results are shown in Table 6.

(2) Credit Rating Based on K-Means Clustering. By setting the number of K-means clustering as 9 , the division results of 9 credit grades can be obtained directly [22], which are listed in columns 1-3 of Table 7. The calculations of credit score interval, interval length, and default loss rate are the same as above, which are, respectively, listed in columns 4-6 of Table 7. The specific results are shown in Table 7.

4.3.2. Test of Credit Rating Model. This study mainly uses two standards to test and compare four credit rating models, which are (1) standard of reasonableness for matching credit 
TABLE 4: Default loss rate of different credit ratings.

\begin{tabular}{lcccccccccc}
\hline $\begin{array}{l}\text { (1) Objective } \\
\begin{array}{l}\text { function } \\
\text { threshold }\end{array}\end{array}$ & $\begin{array}{c}\text { (2) Objective } \\
\text { function value }\end{array}$ & $\begin{array}{c}\text { (3) AAA } \\
\text { rating } \\
\text { LGD }\end{array}$ & $\begin{array}{c}\text { (4) AA } \\
\text { rating } \\
\text { LGD }\end{array}$ & $\begin{array}{c}\text { (5) A } \\
\text { rating } \\
\text { LGD }\end{array}$ & $\begin{array}{c}\text { (6) BBB } \\
\text { rating } \\
\text { LGD }\end{array}$ & $\begin{array}{c}\text { (7) BB } \\
\text { rating } \\
\text { LGD }\end{array}$ & $\begin{array}{c}\text { (8) B } \\
\text { rating } \\
\text { LGD }\end{array}$ & $\begin{array}{c}\text { (9) CCC } \\
\text { rating } \\
\text { LGD }\end{array}$ & $\begin{array}{c}\text { (10) CC } \\
\text { rating } \\
\text { LGD }\end{array}$ & $\begin{array}{c}\text { (11) C } \\
\text { rating } \\
\text { LGD }\end{array}$ \\
\hline \multirow{2}{*}{42196} & 41742 & 0.52 & 5.62 & 8.18 & 11.10 & 15.30 & 22.93 & 37.89 & 94.68 & 100.00 \\
& 42650 & 0.58 & 5.41 & 8.20 & 18.56 & 19.42 & 19.52 & 37.89 & 94.53 & 100.00 \\
\hline 42650 & 42643 & 0.57 & 5.69 & 6.74 & 7.79 & 18.03 & 20.48 & 22.96 & 94.68 & 100.00 \\
& 42657 & 0.53 & 6.08 & 6.61 & 8.10 & 19.40 & 19.61 & 22.96 & 94.53 & 100.00 \\
\hline
\end{tabular}

TABLE 5: Credit rating results of small enterprises.

\begin{tabular}{lccccc}
\hline (1) No. & (2) Sample size & (3) Credit rating & (4) Credit score interval & (5) Interval length & (6) LGD (\%) \\
\hline $1-1458$ & 1458 & AAA & {$[80.8707,100.0000]$} & 19.1293 \\
$1459-2472$ & 1014 & AA & {$[70.4617,80.8707)$} & 10.4090 & 0.52 \\
$2473-2690$ & 218 & A & {$[58.3853,70.4617)$} & 5.49 \\
$2691-2752$ & 62 & BBB & {$[56.6942,58.3853)$} & 1.6911 & 7.65 \\
$2753-3033$ & 281 & BB & {$[47.7085,56.6942)$} & 8.9857 & 15.42 \\
$3034-3099$ & 66 & B & {$[37.1479,47.7085)$} & 4.5161 & 20.84 \\
$3100-3107$ & 8 & CCC & {$[32.6318,37.1479)$} & 31.3853 & 23.01 \\
$3108-3110$ & 3 & CC & {$[0,31.3853)$} & - \\
3111 & 1 & C & 0 & 100.00 \\
\hline
\end{tabular}

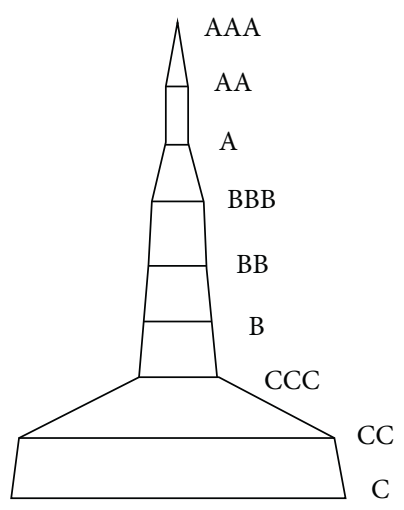

FIGURE 3: Distribution diagram of the relationship between credit rating and default loss rate.

rating with default loss rate and (2) stability standard of credit score interval distribution.

(1) Standard of Reasonableness for Matching Credit Rating with Default Loss Rate. According to column 6 of Tables 6 and 7 , the default loss rate of AAA credit grade and AA credit grade based on the customer number distribution and $\mathrm{K}$-means clustering credit rating model is 0 . This does not satisfy the fact that each credit grade must have a default sample and does not meet the reasonable standard that the default loss rate should rise with the decline of credit grade. The credit rating model constructed in this study strictly meets the inverse relationship between credit grade and default loss rate. The credit rating model based on the distribution of the number of customers is mainly based on the distribution characteristics of "large in the middle and small on both sides" of the number of small enterprises to divide credit ratings; the credit rating model based on K-means clustering mainly clusters small enterprises with similar credit scores into one category, and neither of which takes into account the internal relationship between credit rating and default loss rate, so these two credit rating models are unreasonable.

(2) Stability Standard of Credit Score Interval Distribution. The distribution of credit score interval is stable; that is, the credit score interval should be neither too long nor too short. If the credit score interval is too long, the credit score of small enterprises will change greatly, but the credit grade will remain unchanged. If the credit score interval is too short, the credit grade of small enterprises will change as long as there is a slight change in the credit score. This can mislead banks and other financial institutions in their loan pricing and lending decisions. 
TABLE 6: Credit rating results based on customer number distribution.

\begin{tabular}{lccccc}
\hline (1) No. & (2) Sample proportion & (3) Credit rating & (4) Credit score interval & (5) Interval length & (6) LGD (\%) \\
\hline $1-249$ & 8 & AAA & {$[88.2830,100.0000]$} & 11.7170 & 0.00 \\
$250-747$ & 16 & AA & {$[84.7585,88.2830)$} & 3.5245 & 0.00 \\
$748-1680$ & 30 & A & {$[79.6458,84.7585)$} & 5.1127 \\
$1681-2178$ & 16 & BBB & {$[75.9311,79.6458)$} & 3.7147 & 0.89 \\
$2179-2489$ & 10 & BB & {$[69.2688,75.9311)$} & 6.6623 & 12.2573 \\
$2490-2738$ & 8 & B & {$[57.0115,69.2688)$} & 6.6813 & 8.64 \\
$2739-2925$ & 6 & CCC & {$[50.3302,57.0115)$} & 31.03 \\
$2926-3049$ & 4 & CC & {$[44.3122,50.3302)$} & 31.28 \\
$3050-3111$ & 2 & C & {$[0,44.3122)$} & 34.3122 & 32.04 \\
\hline
\end{tabular}

TABLE 7: Credit rating results based on K-means clustering.

\begin{tabular}{lccccc}
\hline (1) No. & (2) Sample size & (3) Credit rating & (4) Credit score interval & (5) Interval length & (6) LGD (\%) \\
\hline $1-80$ & 80 & AAA & {$[91.8873,100.0000]$} & 8.1127 & 0.00 \\
$81-567$ & 487 & AA & {$[85.9509,91.8873)$} & 5.9364 & 5.6191 \\
$568-1594$ & 1027 & A & {$[80.3318,85.9509)$} & 8.0200 & 0.00 \\
$1595-2398$ & 804 & BBB & {$[72.3118,80.3318)$} & 11.1079 & 6.78 \\
$2399-2660$ & 262 & BB & {$[61.2039,72.3118)$} & 5.90 \\
$2661-2934$ & 274 & B & {$[50.1150,61.2039)$} & 8.5617 & 24.37 \\
$2935-3070$ & 136 & CCC & {$[41.5533,50.1150)$} & 10.1680 & 21.44 \\
$3071-3108$ & 38 & CC & {$[31.3853,41.5533)$} & 31.3853 & 100.00 \\
$3109-3111$ & 3 & C & {$[0,31.3853)$} & & \\
\hline
\end{tabular}

TABLE 8: STDEV stability indicators for different models.

\begin{tabular}{lccc}
\hline (1) Credit rating model & (2) STDEV value & (3) Reasonableness standard & (4) Stability standard \\
\hline Distribution of the number of customers [11] & 12.83 & Inconformity & Inconformity \\
K-means clustering [22] & 7.56 & Inconformity & Conform \\
Default pyramid principle [21] & 17.93 & Conform & Inconformity \\
This study & 9.60 & Conform & Conform \\
\hline
\end{tabular}

The credit rating model based on default pyramid principle [21] is selected for comparative analysis, and the reasons for selecting this literature are as follows: The first reason is that the credit rating model constructed by it and the credit rating model constructed by this study both meet the rationality standard that the corresponding default loss rate keeps rising with the continuous decline of credit grade. The second reason is that the indicator system and empirical data used in this study are the same as those in this literature, and the credit rating results are more comparable.

The stability of credit score interval distribution is tested by STDEV stability index, and the specific results are shown in Table 8.

The STDEV index value of the credit rating model based on K-means clustering is the smallest. However, since this model does not meet the rationality standard of matching credit rating with default loss rate, only the credit rating model based on default pyramid that meets the rationality standard is considered in the comparison model. Because the STDEV value of the credit score interval length of the credit rating model constructed based on the default pyramid principle is larger than that of the interval length of the model constructed in this study, it indicates that the distribution of the credit rating model constructed in this study is more stable.

\section{Conclusion}

\subsection{Main Conclusions}

(1) Empirical results show that when the threshold value of the objective function is 45000 and the maximum value of the objective function is 44951 , the credit score intervals of the nine credit grades from high to low are, respectively, [80.8707, 100.0000], [70.4617, 80.8707], [58.3853, 70.4617], and so forth. The corresponding default loss rates are, respectively, $0.52 \%, 5.49 \%, 7.65 \%$, and so forth.

(2) The comparative analysis shows that the credit rating model constructed in this study is the best, followed by the credit rating model based on default pyramid principle, and the credit rating model based on customer number distribution and K-means clustering is the worst.

\subsection{Main Features}

(1) The maximum ratio of the sum of the dispersions of credit scores between different credit ratings and the sum of the dispersions of credit scores within the same credit rating is taken as the objective function, 
and the default loss rate of the following credit rating strictly larger than the default loss rate of the previous credit rating is taken as the inequality constraint; a nonlinear credit rating optimal partition model is constructed. It ensures that the small enterprises with small credit score gap are of the same credit rating, while the small enterprises with large credit score gap are of different credit ratings, which overcomes the disadvantages of the existing research that only considers the small enterprises with large credit score gap and ignores the small enterprises with small credit score gap.

(2) The approximate solution of the nonlinear optimization model is solved by a recursive algorithm with strong reproducibility and clear structure, and the credit rating of small enterprises is obtained, which shows that the higher the credit rating, the lower the default loss rate, and the credit group of small enterprises is matched with the credit rating.

\section{Data Availability}

The empirical sample in this paper consists of data on loans for 3111 small enterprises from the database of a Chinese commercial bank.

\section{Conflicts of Interest}

The authors declare that they have no conflicts of interest.

\section{Acknowledgments}

The research was supported by Natural Science Foundation of Inner Mongolia Autonomous Region of China (2020MS07009), the National Natural Science Foundation of China (72161033), Key Projects of National Natural Science Foundation of China (71731003), Science and Technology Project of Inner Mongolia Autonomous Region of China (201605053), and Inner Mongolia Autonomous Region Postgraduate Education Innovation Project of China (SR2020082).

\section{References}

[1] Q. X. Sun, Y. F. Liu, and Y. Duan, "The impact of the United States sovereign credit rating downgrading," China Financialyst, vol. 16, pp. 45-46, 2011.

[2] Bank of China, Notice on the Sending of Credit Rating Management Measures for Domestic Institutional Clients of Bank of China, pp. 4-3, Bank of China, Beijing, China, 2003.

[3] Agricultural Bank of China, Notice on Printing and Distributing Measures of Customer Credit Rating of Agricultural Bank of China, pp. 5-6, Agricultural Bank of China, Beijing, China, 2003.

[4] T. H. Moon, Y. Kim, and S. Y. Sohn, "Technology credit rating system for funding SMEs," Journal of the Operational Research Society, vol. 62, no. 4, pp. 608-615, 2011.

[5] G. Gupton, C. Finger, and M. Bhatia, CreditMetrics - Technical Document, pp. 5-22, J. P. Morgan \& Co. Incorporated, New York, NY, USA, 1997.
[6] M. Lyra, J. Paha, S. Paterlini, and P. Winker, "Optimization heuristics for determining internal rating grading scales," Computational Statistics \& Data Analysis, vol. 54, no. 11, pp. 2693-2706, 2010.

[7] J. B. Zhang, "A new method for calculating the probability of default of credit rating based on complete information," The Study of Quantitative and Technical Economics, vol. 35, no. 6, pp. 149-164, 2018.

[8] Z. Y. Zhu, W. H. Su, and Q. X. Wang, "Credit risk assessment of small and medium-sized enterprises under the financing environment of the New Third Board," Statistics and Information Forum, vol. 33, no. 10, pp. 107-113, 2018.

[9] J.-C. Duan and S. Li, "Enhanced PD-implied ratings by targeting the credit rating migration matrix," The Journal of Finance and Data Science, vol. 7, pp. 115-125, 2021.

[10] G. T. Chi, M. D. Pan, and F. Qi, "The design and application of a credit risk rating model for banks based on small samples," The Study of Quantitative and Technical Economics, vol. 31, no. 6, pp. 02-116, 2014.

[11] G. T. Chi, M. D. Pan, and Y. Q. Chen, "Rural households' credit evaluation model based on comprehensive discriminant ability," Management Review, vol. 27, no. 06, pp. 42-57, 2015.

[12] Y. Zhang and G. Chi, "A credit rating model based on a customer number bell-shaped distribution," Management Decision, vol. 56, no. 5, pp. 987-1007, 2018.

[13] Z. C. Zhao, G. T. Chi, and M. D. Pan, "An optimization method for credit rating based on the maximum credit difference degree," Systems Engineering Theory \& Practice, vol. 37, no. 10, pp. 2539-2554, 2017.

[14] B. F. Shi, J. Wang, and G. T. Chi, "Inclusivity finance, bank credit and merchant microfinance: a perspective of risk level matching," Chinese Management Science, vol. 25, no. 9, pp. 28-36, 2017.

[15] G. T. Chi and S. L. Yu, "The credit rating method based on the maximum default discriminating ability," Journal of Management Science, vol. 22, no. 11, pp. 106-126, 2019.

[16] B. Shi, X. Zhao, B. Wu, and Y. Dong, "Credit rating and microfinance lending decisions based on loss given default (LGD)," Finance Research Letters, vol. 30, pp. 124-129, 2019.

[17] B. Shi, G. Chi, and W. Li, "Exploring the mismatch between credit ratings and loss-given-default: a credit risk approach," Economic Modelling, vol. 85, pp. 420-428, 2020.

[18] Y. Zhou, "Credit rating model of small industrial enterprises based on information gain," Operations research and management, vol. 30, no. 1, pp. 209-216, 2021.

[19] X. S. Ren and X. L. Yu, Multivariate Statistical Analysis, China Statistics Press, Beijing, China, 2010.

[20] F. M. Zhang, W. J. Hua, and R. Y. Li, "Stability analysis of several comprehensive evaluation methods," System Science and Mathematics, vol. 39, no. 4, pp. 595-610, 2019.

[21] B. F. Shi, Research on Credit Rating Model of Small Enterprise Based on Default Pyramid Principle, Dalian University of Technology, Dalian, China, 2014.

[22] F. L. Raquel, "Modelling of insurers' rating determinants. An application of machine learning techniques and statistical models," European Journal of Operational Research, vol. 183, no. 3, pp. 1488-1512, 2007. 